\title{
Mass Spectrometric and Langmuir Probe Measurements in Inductively Coupled Plasmas in $\mathrm{Ar}, \mathrm{CHF}_{3} / \mathrm{Ar}$ and $\mathrm{CHF}_{3} / \mathrm{Ar} / \mathrm{O}_{2}$ Mixtures \\ J. S. Kim ${ }^{\dagger}$, M.V.V.S. Rao , M. A. Cappelli ${ }^{\dagger}$, S. P. Sharma, and M. Meyyappan \\ Plasma Research Laboratory, NASA-Ames Research Center \\ Moffett Field, CA 94035, USA
}

\begin{abstract}
Absolute fluxes and energy distributions of ions in inductively coupled plasmas of $\mathrm{Ar}, \mathrm{CHF}_{3} / \mathrm{Ar}$, and $\mathrm{CHF}_{3} /$ $\mathrm{Ar} / \mathrm{O}_{2}$ have been measured. These plasmas were generated in a Gaseous Electronics Conference (GEC) cell modified for inductive coupling at pressures $10-50 \mathrm{mTorr}$ and $100-300 \mathrm{~W}$ of $13.56 \mathrm{MHz}$ radio frequency (RF) power in various feedgas mixtures. In pure Ar plasmas, the $\mathrm{Ar}^{+}$flux increases linearly with pressure as well as $\mathrm{RF}$ power. Total ion flux in $\mathrm{CHF}_{3}$ mixtures decreases with increase in pressure and also $\mathrm{CHF}_{3}$ concentration. Relative ion fluxes observed in the present studies are analyzed with the help of available cross sections for electron impact ionization and charge-exchange ion-molecule reactions. Measurements of plasma potential, electron and ion number densities, electron energy distribution function, and mean electron energy have also been made in the center of the plasma with a RF compensated Langmuir probe. Plasma potential values are compared with the mean ion energies determined from the measured ion energy distributions and are consistent. Electron temperature, plasma potential, and mean ion energy vary inversely with pressure, but increase with $\mathrm{CHF}_{3}$ content in the mixture.
\end{abstract}

\footnotetext{
"ELORET, e-mail: rmangina@mail.arc.nasa.gov, Author for correspondence

${ }^{\dagger}$ Mechanical Engineering Department, Stanford University, Stanford, CA 94305

- Currently at Lam Research, Fremont, CA.
} 


\section{Introduction}

Low pressure plasma reactors are indispensable for etching and deposition of materials in microelectronic device fabrication. However, many plasma processes suffer from stability and reliability problems leading to a compromise in performance and increased cost for the semiconductor industry. Although a great deal of research has been done on many processing plasmas, little is known about the gas-phase and surface reactions that are critical in etch and deposition processes, and how these reactions are influenced by the variation in operating conditions. Such a lack of understanding has also hindered the development of process models that can aid in the scaling and improvement of plasma reactors. Characterization of plasma discharges is necessary to improve understanding, performance and control of the processing plasmas and to verify reactor models. Characterization also helps to optimize parameters such as input power, gas flow rate and pressure, composition of gas mixture, etc., in the reactor.

Fluorocarbon gas plasmas have been routinely employed in selective etching of silicon dioxide over silicon ${ }^{1,2}$. $C F_{x}$ radicals created in the plasma thermally diffuse onto the wafer surface and get deposited as a precursor to a fluorocarbon polymer. Formation of a passivating film on the silicon surface is thought to be a key mechanism for selective etching. ${ }^{3-6}$ These radicals passivate $\mathrm{SiO}_{2}$ surfaces to a lesser degree than $\mathrm{Si}$ surfaces because the carbon in the films can react with the oxygen in $\mathrm{SiO}_{2}$ resulting in volatile products ${ }^{7}$ such as $\mathrm{CO}, \mathrm{CO}_{2}, \mathrm{COF}$, and $\mathrm{COF}_{2}$. One troublesome issue in high-density fluorocarbon plasmas is the high degree of molecular dissociation that produces an abundance of atomic fluorine and the consequent inadequate suppression of $\mathrm{Si}$ etch. Concentrations of fluorocarbon species and thus selectivity is controlled by source gas dilution with additives such as $\mathrm{O}_{2}, \mathrm{H}_{2}$, and Ar. As added benefits, oxygen helps in preventing excessive carbon deposition on the reactor walls and argon helps in maintaining stable discharges.

Among the fluorocarbon gases, ozone-friendly trifluoromethane $\left(\mathrm{CHF}_{3}\right)$ and its mixtures with other gases are commonly used in etching. However, electron kinetics and plasma potential 
data have not yet been reported. Moreover, most of the measurements hitherto on $\mathrm{CHF}_{3}$ and its mixtures have been mainly concentrated on relative composition of neutrals and ions, ${ }^{8,9}$ surface chemistry of Si substrates in pure $\mathrm{CHF}_{3} \mathrm{ICP}$ discharges, ${ }^{10-14} \mathrm{SiO}_{2}$ to $\mathrm{Si}$ selectivity mechanisms in

high density $\mathrm{CHF}_{3} / \mathrm{H}_{2}$ electron cyclotron resonance (ECR) discharges, ${ }^{15,16}$ and fluorocarbon film deposition in $\mathrm{CHF}_{3} / \mathrm{CO}$ magnetron-enhanced reactive ion etching, ${ }^{17}$ but very little on ion kinetics $^{18}$. Recently, studies of ICPs using a GEC cell have been reported on relative composition of ions and neutrals ${ }^{8.9}$ in pure $\mathrm{CHF}_{3}$, and ion energy distributions (IEDs) and absolute fluxes of ions in pure $\mathrm{CHF}_{3}$ and $\mathrm{CHF}_{3} / \mathrm{Ar}$ mixtures in a limited pressure range. ${ }^{18}$ In recent years there has also been an increased effort aimed at developing models, which have self-consistently combined plasma and surface processes to simulate low-pressure fluorocarbon ${ }^{19,20}$ and oxygen $^{21,22}$ systems.

In this study, by using an electrostatic ion energy analyzer in conjunction with a quadrupole mass filter, we have investigated ion energy distributions (IEDs) and absolute fluxes of ionic species in inductively coupled plasmas of $\mathrm{Ar}, \mathrm{CHF}_{3} / \mathrm{Ar}$, and $\mathrm{CHF}_{3} / \mathrm{Ar} / \mathrm{O}_{2}$ mixtures generated in the GEC cell at gas pressures ranging from 10-50 mTorr and RF powers from 100$300 \mathrm{~W}$. Further, by using an RF-compensated Langmuir probe, we have also measured key plasma parameters: electron number density $\left(n_{e}\right)$, ion number density $\left(n_{i}^{+}\right)$, electron energy distribution function (EEDF), mean electron energy $\left(\left\langle\varepsilon_{e}\right\rangle\right)$, electron temperature $\left(T_{e}\right)$, and plasma potential $\left(V_{p}\right)$.

\section{Apparatus and Experiment}

\section{A. GEC Reference Cell}

Figure 1 shows a schematic of the experimental arrangement consisting of a GEC reference cell, a $13.56 \mathrm{MHz}$ radio frequency (RF) power supply and matching network, an electrostatic quadrapole plasma analyzer (EQPA), and a Langmuir probe. A base pressure of about $5 \times 10^{-8}$ Torr in the chamber is achieved by using a 270 liters/sec turbo molecular pump backed by a 400 liters/minute mechanical pump. A flat 5 -turn and $3.5^{\prime \prime}$ diameter inductive coil, 
made of $0.125^{\prime \prime}$ diameter copper tube with a low aspect ratio (length/diameter $<1$ ), is fabricated and assembled in place of the plane upper electrode of the original GEC cell. ${ }^{23,24}$ The inductive coil is mounted at the top of the chamber and is concentric with the center of the chamber to maintain discharge symmetry. It is insulated from the plasma by a quartz window of $0.375^{\prime \prime}$ thick, and 5" diameter. The lower-electrode, which is a plane of 4 " diameter and made of 304 stainless steel, is integrated both electrically and mechanically to the EQPA (Fig. 1). The distance between the quartz window and lower electrode is about $1.5^{\prime \prime}$.

The plasma is powered by a $13.56 \mathrm{MHz}$ RF-power supply (Advanced Energy RFXII 1250) connected to the inductive coil through a matching network consisting of two air-dielectric variable capacitors as shown in Fig. 1. The matching network is placed very close to the inductive coil to minimize any resistive losses. The input RF power is calibrated with a Throughline watt meter (Bird Electronics Corp.) and stable better than 1\%. The lower electrode, which can also be RF powered (Comdel CPS 1001S power supply) through an impedance matching network (Comdel CPMX-2500), is grounded in the present measurements. Whenever electronegative gases such as $\mathrm{CHF}_{3}$ and $\mathrm{O}_{2}$ are present in the feed gas, it is almost impossible to start the discharge with the upper coil without powering the lower-electrode to ignite the discharge. Once the discharge is initiated, the RF bias on the lower-electrode is removed and the lower electrode is connected back to ground. The lower electrode is surrounded by a grounded heat shield and water-cooled to maintain a steady state temperature. In the absence of cooling it is observed that, with the plasma on, the temperature on the electrode continues to rise with time and consequently causes outgassing the nearby O-rings which seal the EQPA from the GEC cell. As a result the pressure in the EQPA chamber exceeds $5 \times 10^{-6}$ Torr, which is the minimum required pressure for operating the ion detector (channeltron). Recently, Schaepkens et al. ${ }^{25}$ observed that the thickness of the polymer layer on the wafer and the density of radicals in the gas-phase are functions of the wall temperature. Therefore, it is important to maintain a stable temperature on the electrode surface during data collection.

The voltage drop across the coil and the root-mean square discharge current are monitored by a high voltage probe (Tektronix P6015A) and a Hall probe (Pearson 2878), 
respectively, and their wave forms are stored in a dual channel digital oscilloscope (Tektronix TDS 340A and 2440). For measuring the total impedance of the circuit, these two probes are connected at the input end of the inductive coil and also very close to each other to avoid any phase difference. The RF-power deposited into the plasma is dependent on various electrical loads such as plasma impedance, inductive coil impedance, parasitic capacitive loading, and external impedance of the RF-power circuit. Therefore, the total input power is equal to the sum of the power deposited into the plasma and the power losses due to other electrical loads. In order to quantify the actual power dissipated into the plasma, various electrical parameters of the power circuit are measured. To determine the coupling efficiency, defined as the ratio of the RFpower dissipated $\left(P_{d i s}\right)$ into the plasma to the input RF-power $\left(P_{i n}\right)$ to the coil, the reflected power is measured by powering the inductive coil with plasma-on and without feed-gas (highvacuum) in the GEC cell. The matching network is tuned for a minimum reflected power with plasma-on. The reflected power with plasma on is typically about 0-1 Watt at all input powers used in the present study. Since the reflected power under plasma-on condition is negligible, the reflected power under vacuum is the power deposited into the plasma and is plotted in Fig. 2 as function of input power at different gas pressures. The coupling efficiency, i.e., the power transfer efficiency $\xi=P_{\text {dis }} / P_{\text {in }}$ is determined to be $60-80 \%$ depending on the gas pressure. The inductive coil is silver plated to avoid oxidation and is internally cooled with chilled de-ionized water to minimize resistive and thermal losses. Moreover, the coupling efficiency is slightly improved with water-cooling.

In order to ensure reproducibility and reliability of our results a set of test procedures is followed during all runs. For making new measurements, the GEC cell (electrodes, chamber walls, and quartz window) is thoroughly cleaned and left under vacuum to achieve lower than $2.0 \times 10^{-7}$ Torr thus ensuring negligible impurity level in the chamber (e.g. $\mathrm{H}_{2} \mathrm{O}, \mathrm{N}_{2}$, and $\mathrm{O}_{2}$ ). A typical base pressure of $<10^{-8}$ Torr in the GEC cell and $<10^{-9}$ Torr in the EQPA is obtained in a couple of days of pumping. The Langmuir probe tip is replaced on a regular basis. The GEC cell is tested and standardized by using both mass spectrometry and Langmuir probe measurements for inductively coupled Ar plasmas and comparing the Ar results with available data in the literature. ${ }^{26,27}$ The Ar data in turn serves as reference for calibration of new measurements for a 
gas or a gas mixture of interest. Before making any new measurements, as a practice we routinely run Ar plasmas to make sure that the Ar data is consistent within acceptable error limits. To ensure uniform mixing of gas mixture before it reaches the chamber, the gases of interest are pre-mixed in one of the 4 " radial ports to provide desired mixture ratios. The gas flow rates are kept constant by using mass flow controllers (Tylan General FC-2900M for Ar, DFC-2900M for $\mathrm{CHF}_{3}$, and FC2950M for $\mathrm{O}_{2}$ ). The chamber pressure is monitored by a Baratron absolute pressure gauge (MKS $122 \mathrm{~B}$ ), and is constant within $\pm 1 \%$. An exhaust throttle valve (MKS $253 \mathrm{~B}$ ), which is installed between the GEC Cell and the mechanical pump, controls the gas flow out of the GEC Cell. The flow meters and pressure settings are controlled by a personal computer using a LabView software program.

\section{B. Electrostatic Quadrupole Plasma Analyzer (EQPA)}

The high transmission EQPA (Hiden Analytical Ltd.) shown in Fig. 1 consists of a combination of ion transporting lenses, $45^{\circ}$ sector-field ion energy analyzer, quadrupole mass filter (QMF), and ion detector (channeltron) for the study of both energies and masses of positive ions, negative ions, radicals, and neutrals. The QMF identifies various ions according to their mass to charge ratio $(M / q)$, and the $45^{\circ}$ sector field analyzer in conjunction with the QMF measures the IED for each $M / q$ selected ion. A built-in variable energy electron-impact source in the EQPA serves to measure the radicals and neutrals coming out of the plasma by measuring their appearance ionization potential profiles as a function of electron impact energy. The polarities of various lenses in the EQPA can be changed for either positive or negative ion detection. The operating settings of each component of the EQPA are computer-controlled by software "Mass-Soft". A $25 \mu \mathrm{m}$ orifice in the center of the lower-electrode separates the GEC chamber and the EQPA chamber. The EQPA chamber is differentially pumped to a base pressure of $2 \times 10^{-9}$ Torr by a turbo molecular pump (210 liter/s of Pfeiffer TPU 210) with a backing mechanical pump $\left(16.5 \mathrm{~m}^{3} / \mathrm{hr}\right.$, Leybold D16B).

Transmission efficiency of the ions as they travel through the EQPA is found to be very much dependent on their mass to charge ratio $(M / q)$. Consequently, for a given ion flux, the 
count rate of two ions of different masses is different. In order to correct for ion transmission efficiency, the EQPA is calibrated by the following procedure. A premixed gas mixture of known composition $(20 \% \mathrm{He}, 20 \% \mathrm{Ar}, 20 \% \mathrm{Ne}, 20 \% \mathrm{Kr}$, and $20 \% \mathrm{Xe}$, whose isotope ratios and ionization cross sections are well known in the literature) is flowed into the GEC cell at a fixed pressure. At the entrance of the EQPA the gas mixture is ionized at a fixed incident electronenergy and electron-current by using the built-in electron-impact source. All the rare gas ions of different masses are then accelerated to a desired energy by biasing the accelerating grid at a fixed voltage (e.g., 10 Volts) such that all ions in the electron-impact ionization source gain the same energy irrespective of their masses. This ensures that, for a given fixed energy, the ionenergy dependent transmission efficiency of the EQPA is unity for ions of different masses. The energy scale of EQPA is accurate to within $\pm 0.1 \mathrm{eV}$. The ions extracted from the electronimpact source are then transported onto the ion detector through the $45^{\circ}$ electrostatic field analyzer and the triple quadrupole mass filter. Mass transmission efficiency correction factors for each $M / q$ are then obtained by normalizing their ion signals with respect to their known ionization cross sections. This procedure is repeated whenever any geometrical changes are made in positioning the ion transporting optics of the EQPA.

\section{Ion flux and Ion energy Distribution Measurements}

Ions accelerated through the plasma sheath and striking the lower-electrode are sampled through the $25 \mu \mathrm{m}$ orifice in the center of the lower-electrode and drawn toward the EQPA by an extractor. The extractor, which is the closest EQPA element to the lower-electrode, is biased at a very low voltage ( -2 volts) to make sure that its field penetration into the plasma is insignificant and does not influence the ion energies. When the GEC cell is operated at 10-50 mTorr, differential pumping of the EQPA takes care of the gas load through the $25 \mu \mathrm{m}$ orifice on the lower-electrode and maintains high vacuum in the EQPA $\left(<1 \times 10^{-7}\right.$ Torr $)$ for the safe operation of the ion detector. Moreover, the low pressure environment in the EQPA increases the mean free path of the sampled species and helps to prevent enroute gas phase collisions. This ensures that no ionization or ion-molecule collisions occur inside the EQPA and all the detected ions directly originate from the plasma. The extractor has an aperture of about $2 \mathrm{~mm}$ in diameter and 
is positioned about $7 \mathrm{~mm}$ below the lower electrode. The geometry of the ion sampling arrangement is such that only those ions passing through the solid angle (about $16^{\circ}$ subtended by the extractor aperture with respect to the $25 \mu \mathrm{m}$ ion-sampling orifice) enter into the EQPA. These ions are transported by a set of ion transporting and steering lenses, which focus them into the $45^{\circ}$ sector-field electrostatic energy analyzer for energy analysis and then into the QMF for $M / q$ selection. Subsequently, the ion detector positioned at the end of the QMF detects the incident ions. The detected ion signals are processed by a set of conventional electronic circuits and the data are stored in a personal computer. The IED for each $M / q$ selected ion is measured by varying the field across the plates of the $45^{\circ}$ sector-field electrostatic energy analyzer. The area under the IED curve so obtained for each ion is a measure of its transmitted current through the EQPA. The sum of all individual ion fluxes represents the total ion flux.

While the ions travel towards the lower electrode at high axial velocities, they possess a certain radial velocity component due to collisional effects in the plasma. As a result, when ions pass through the $25 \mu \mathrm{m}$ orifice, they emerge as a cone having a solid angle whose broadening depends on operating conditions in the GEC cell, (gas pressure, RF-power, and plasma species). This solid angle is always observed to be more than the solid angle defined by the geometry of the aperture $\left(16^{\circ}\right)$. For example, as the pressure is lowered, fewer collisions take place in the bulk plasma and the electron temperature and plasma potential increase, then ions acquire higher directional velocities towards the lower electrode with narrow impact angles; this means the transmitted current through the orifice into the EQPA will increase. In order to determine the total ion flux exiting through the ion sampling orifice, which is the practical quantity of interest, the following procedure is used. An electrometer (Keithly Model 6512) is connected to the extractor to monitor and measure a stray ion current $\left(I_{\text {stray }}\right)$ due to the ions falling onto the extractor front surface, which is about $10 \mathrm{~mm}$ in diameter. This measurement does not include the contribution of transmitted ion current $\left(I_{\text {iran }}\right)$ through the extractor under normal operating conditions of the EQPA for positive ion detection, i.e., when the ion optics are negatively biased and tuned for the best transmission of the positive ions. In other words, $I_{\text {stray }}$ is a measure of the ion current due to ions which remain outside of the $2 \mathrm{~mm}$ extractor hole and do not enter into the EQPA. In order to get the total ion current $\left(I_{\text {total }}=I_{\text {trans }}+I_{\text {stray }}\right)$ exiting through the $25 \mu \mathrm{m}$ ion- 
sampling orifice, the transmitted ions are blocked and collected on the extractor before they enter into the EQPA by positively biasing the ion optics in front of the $45^{\circ}$ electrostatic sector field analyzer. The difference between two current measurements with and without bias, i.e., $I_{\text {trans }}=$ $I_{\text {rotal }}-I_{\text {stray }}$, is a measure of the ion flux that enters the EQPA after passing through the extractor aperture. The total ion current, $I_{\text {total }}$, is distributed among the detected ions according to their respective relative areas under the IED curves, neglecting differences in the shape of the total and transmitted IEDS. Absolute individual ion fluxes can be obtained by integrating the appropriate curves.

In the case of $\mathrm{Ar}$, measurements were made at gas pressures ranging from 10-50 mTorr and at $\mathrm{RF}$ powers from $100-300 \mathrm{~W}$. For $\mathrm{CHF}_{3} / \mathrm{Ar}$ mixtures, measurements were made at $200 \mathrm{~W}$ in three mixtures of $\mathrm{CHF}_{3} / \mathrm{Ar}$ : $20 / 80,50 / 50$ and $80 / 20 \%$ and at pressures $10,20,30$, and $50 \mathrm{mTorr}$. When $\mathrm{CHF}_{3}$ was added to $\mathrm{Ar}$, discharge instability was observed below $200 \mathrm{~W}$ at all pressures, which has also been reported by Wang et al. ${ }^{18}$ This could be due to the electronegative nature of $\mathrm{CHF}_{3}$, leading to a rapid build up of negative ions $\left(\mathrm{F}^{-}\right.$and $\left.\mathrm{CF}_{3}{ }^{-}\right)$at the expense of a reduction in electron density. This rapid drop in electron density causes a loss of the quasiequlibrium state of the plasma, hence the discharge decays. A similar behavior was also observed in $\mathrm{CHF}_{3} / \mathrm{Ar} / \mathrm{O}_{2}$ discharges. Admixing $\mathrm{O}_{2}$ to $\mathrm{CHF}_{3} / \mathrm{Ar}$, the discharge was found to be unstable below $30 \mathrm{mTorr}$, so the data for $\mathrm{CHF}_{3} / \mathrm{Ar} / \mathrm{O}_{2}$ were obtained at 30 and $50 \mathrm{mTorr}$ for two mixture ratios $\mathrm{CHF}_{3} / \mathrm{Ar} / \mathrm{O}_{2}: 40 / 40 / 20$ and $60 / 20 / 20 \%$ at 200 and $300 \mathrm{~W}$ RF powers. When the lower electrode, the chamber walls, and the quartz window were cleaned thoroughly, the discharge was found to be stable for some time (a few hours) at lower pressures indicating that the surface condition of materials exposed to the plasma is also important to maintain a stable discharge. When the discharge was stable, a quick set of measurements of the total ion flux was made at 10 and 20 mTorr in $\mathrm{CHF}_{3} / \mathrm{Ar} / \mathrm{O}_{2}$ mixtures. A summary of all the total and transmitted ion fluxes is presented in Table 1. Individual ion fluxes are reported in Tables 2 and 3. The results are discussed in Section III.

\section{Langmuir probe Measurements}


Despite their obvious intrusiveness, Langmuir probe measurements have been extensively used for plasma characterization since no other technique can provide information simultaneously about EEDF, $\langle\varnothing\rangle, n_{e}, n_{i}{ }^{+}, T_{e}$, and $V_{p}$. Moreover, it is relatively inexpensive and

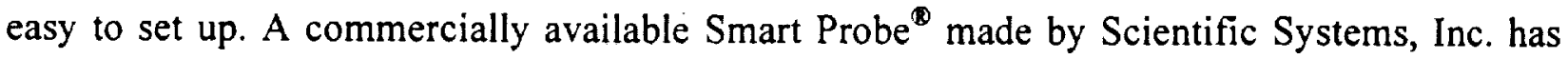
been used in the present studies. The setup comes with a built-in data analysis software based on well established theory for the interpretation of the probe traces. ${ }^{28}$ The Smart Probe ${ }^{2}$ sensor senses the high frequency fluctuations in plasma potential and compensates for it so that the probe effectively sees the dc bias but not the alternating (RF) potential. RF compensation involves increasing the probe to ground impedance with respect to the plasma to probe sheath impedance. This ensures that a significant portion of the $R F$ voltage appears across the probe to ground impedance and not the plasma to probe sheath impedance. Introducing a pair of selfresonant inductors with their intrinsic capacitance close to the driving frequency increases the probe impedance. The inductors are placed inside the ceramic tube close to the probe tip and the plasma chamber to eliminate the effects of stray capacitance. If the inductors are not placed very close to the probe tip, any stray capacitance will shunt the effect of the inductors. The Smart Probe also uses a compensation electrode in contact with the plasma that is capacitively coupled to the probe tip. The large capacitance and low impedance of this electrode dominates and shunts the probe to plasma sheath impedance. As a result the sheath impedance becomes independent of probe bias and is not affected by the external bias on the probe tip.

The body of the probe is made of a cylindrical and hollow ceramic tube with a tapered ceramic tip holder. A platinum wire, $380 \mu \mathrm{m}$ in diameter and $2.5 \mathrm{~mm}$ in length, is used as the probe tip. The probe tip is inserted into the tip holder and is held by means of set screws. A smaller probe tip is preferred to minimize perturbation to the local plasma and to draw low current in order not to overheat and melt the tip to its melting point. The probe is mounted on a linear motion feedthrough and inserted into the plasma through one of the radial ports. The desired motion of the probe is provided by a computer controlled stepper motor (Superior Electronic M061-CS02), which is attached at the end of the linear motion feed-through (Keithley MSTEP-5). Thus the probe can be used to acquire data at any desired radial position in the plasma. When the probe is immersed inside the discharge, inductors placed inside the 
probe and the probe holder are cooled continuously by flowing dry air onto them, thus avoiding overheating of the inductors and electrical wiring by the plasma radiation.

For each discharge condition, the Langmuir probe is moved into the plasma center in the mid-plane of the plasma discharge. Before collecting any data, the probe-tip is cleaned thoroughly of possible contamination by negatively pulse biasing such that the tip becomes white-hot by energetic ion bombardment within the plasma. This procedure is repeated between each data point collection to ensure good quality of the data. For actual data collection, the sweep voltage range on the tip is set to a desired value to cover the range from the ion saturation current to the electron saturation current. Each data point is sampled several times in order to obtain a smooth current-voltage $(I-V)$ curve. EEDF measurements are also made using the Smart

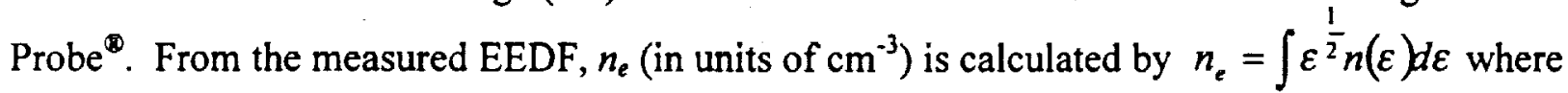
$\varepsilon$ is the electron energy in $\mathrm{eV}$ and $n(\varepsilon)$ is the EEDF in $\mathrm{cm}^{-3} \mathrm{eV}^{-3 / 2}$. The EEDF in nonMaxwellian plasmas, which is the case in the present studies, is related to the second derivative of the electron current $\left(I_{e}^{*}\right)$ with respect to the electron energy as ${ }^{29}$

$$
n(\varepsilon)=n_{e} f(\varepsilon)=\frac{2 I_{e}^{\prime \prime}}{e A_{p}}\left(\frac{2 m_{e} \varepsilon}{e}\right)^{\frac{1}{2}}
$$

Here energy $\varepsilon=V-V_{p}, V$ is the applied bias voltage to the probe tip, $V_{p}$ is the plasma potential, $I_{e}^{*}$ is the second derivative of electron current, $A_{p}$ is the probe tip surface area exposed to the plasma, $e$ is the elementary charge, $m_{e}$ is the electron mass, and $f(\varepsilon)$ is the normalized EEDF. During the data sampling, $I_{e}^{*}$ is dynamically calculated numerically from the probe current measurements and averaged over 1000 points at each bias voltage. From the measured EEDF the following relation is used to obtain the mean electron energy $\langle\varepsilon$ 


$$
<\varepsilon>=\frac{\int_{0}^{\infty} \varepsilon^{\frac{1}{2}} n(\varepsilon) \varepsilon d \varepsilon}{\int_{0}^{\infty} \varepsilon^{\frac{1}{2}} n(\varepsilon) d \varepsilon}
$$

and an effective electron temperature $\left(T_{e}\right)$ for each condition is calculated as $2 / 3\langle\varepsilon\rangle . V_{p}$ is determined from the cut-off point on the voltage axis by the second derivative $I_{e}^{*}$ of the $I-V$ curve, i.e., $d^{2} I_{e} / d V^{2}=0$. By increasing the negative bias with respect to $V_{p}$, the point is reached where no electrons reach the probe tip and only positive ions are collected on it. This ion saturation region yields the $n_{i}^{+}$in the plasma and is calculated, using the modified Laframboise theory ${ }^{30}$ in which the thermal flux is replaced by the Bohm flux:

$$
n_{i}^{+}=\frac{I_{i}^{+}}{1.6 A_{p}}\left(\frac{2 \pi M_{i}^{+}}{e^{2} T_{e}}\right)^{\frac{1}{2}}
$$

where $\mathrm{I}_{i}^{+}$and $\mathrm{M}_{i}^{+}$represent the positive ion current and ion mass, respectively. In the case of Ar plasmas $\mathrm{Ar}^{+}\left(\mathrm{Mi}^{+}=40 \mathrm{amu}\right)$ is the only abundant ion, whereas a large number of ions is found in $\mathrm{CHF}_{3} / \mathrm{Ar}$ and $\mathrm{CHF}_{3} / \mathrm{O}_{2} / \mathrm{Ar}$ mixtures in which case the mass of the most dominant ion is used in calculating $n_{i}^{+}$.

\section{RESULTS AND DISCUSSION}

\section{A. Argon}

Ion fluxes and IEDs were measured in Ar plasmas for the purpose of comparison with previous GEC cell results. The present data is consistent with earlier observations ${ }^{26,27}$ that singly. charged $\mathrm{Ar}^{+}$is the most dominant ion and the presence of $\mathrm{Ar}^{2+}$ is almost negligible at all discharge conditions studied here. Fig. 3a shows the $\mathrm{Ar}^{+}$flux as a function of pressure along with GEC data from other groups. ${ }^{26,27}$ The flux values of this work are also listed in Table 1. In Fig. 3a the $\mathrm{Ar}^{+}$flux increases with gas pressure and RF-power. Our data on ion flux is in good 
agreement with that of Woodworth et al. ${ }^{26}$ at 200 and $300 \mathrm{~W}$; at $100 \mathrm{~W}$ their values are about $25 \%$ lower at all pressures but the difference is well within the combined uncertainties in both sets of data. The uncertainty in our data is about $15 \%$ which is the same as in the measurements by Woodworth et al. In addition, their lower electrode is not water-cooled like ours. The data of Wang and Olthoff (marked as NIST in Fig. 3), ${ }^{27}$ are lower by about a factor of two at $100 \mathrm{~W}$ and about $35 \%$ at $300 \mathrm{~W}$. The measurement techniques in the NIST work and ours are mostly similar except that their applied voltage on the extractor of the EQPA was -100 V compared to $-2 \mathrm{~V}$ in our case, and our lower electrode is water-cooled. Other possible reasons for the discrepancy might be due to determination of orifice size in cach case, difference in induction coil size, possible differences in power coupling efficiency, electrode surface conditions, and uncertainties in operating pressures and powers.

Typical IEDs of $\mathrm{Ar}^{+}$for a few representative conditions are shown in Fig. 3b. The shape and energy dispersion of the IED for similar ICP conditions have been discussed by Kortsagen and Zethoff. ${ }^{31}$ Their analytical calculations show that the product of applied frequency $(\omega)$ and the ion transit time through the sheath $\left(\tau_{t}\right)$ is a critical parameter in describing the shape of the IED. If $\omega \tau_{>}>>1$, the ions will exhibit a narrow single peak. In high density plasmas, the sheath is thin and collisionless, and the ion mean free path is an order of magnitude larger than the sheath thickness satisfying the condition $\omega \tau_{p}>1$. Then ions experience many RF-field oscillations while in transit through the sheath and respond to the time averaged sheath potential. As a result, ions will have only a single-energy peak with a narrow energy spread as they gain energy by acceleration due to sheath voltage which is predominantly dc with only a small ac component causing spatial variations in the sheath potential. The broadening of the IED is a combined effect of the initial ion energy in the presheath, the thermal ion temperature $\left(T_{i}\right.$, which is typically $<0.5 \mathrm{eV}$ ) in the bulk plasma, the axial modulations in plasma sheath due to RF fluctuations, the stray capacitive component between coil and plasma, and the instrumental energy resolution $(\sim 1$ $\mathrm{eV}$ ). The full width at half maximum (FWHM) of the IEDs of $\mathrm{Ar}^{+}$is about $3.0 \pm 0.1 \mathrm{eV}$, which is about the same as reported by Woodworth et $a l^{26}(2.8 \mathrm{eV})$ and Wang and Olthoff ${ }^{27}(3.1 \mathrm{eV})$. Woodworth $e t a l^{26}$, using a Faraday shield ${ }^{32}$ between the induction coil and the quartz window, observed a decrease in the capacitive component and an eventual decrease in the width of the 
IED by $0.7 \mathrm{eV}$. However, our investigations showed that the Faraday shield has an insignificant effect on the IEDs and hence the results reported here are from measurements without a Faraday shield. As shown in Fig. $3 \mathrm{~b}$ the mean ion energy $\left(\left\langle E_{p}\right\rangle\right)$ determined from the measured IED is nearly independent of the RF power, except a small shift towards higher energy with increase of power at lower pressures. $\left\langle E_{p}>\right.$ depends on $V_{p}$, and it is well known that power has only a minor effect on $T_{e}$ and $V_{p}{ }^{33}$. The $\left\langle E_{p}\right\rangle$, however, decreases with increase in pressure (Fig. 3c) since $V_{p}$ is a strong function of the gas pressure; this trend is also consistent with the $V_{p}$ measurements from the Langmuir probe. The measured $\langle E>$ values, which are accurate to $\pm 0.5 \mathrm{eV}$, agree with published data ${ }^{26,27}$ (aiso shown in Fig. 3c).

Figure 4 shows Langmuir probe measurements in pure argon. As mentioned above, both electron temperature and plasma potential are not significantly affected by power, but decrease when the pressure increases. Note that $V_{p}$ values are higher by about 3-4 eV than the mean ion energy (measured at the electrode) in Fig. 3c. The mean ion energy is in fact proportional to the potential difference between the plasma $\left(V_{p}\right)$ and the electrode. The electron and ion densities in pure argon increase with both power and pressure in the range investigated here. To check the consistency of the values, measurements were repeated by varying the probe tip and gas flow rate and the values were found to be reproducible within $15 \%$. Note that a change in gas flow can have a slight effect in electron, ion, and neutral densities. The behavior in Fig. $4 \mathrm{~b}$ is consistent with simple analytical models for electropositive plasmas ${ }^{33}$. In general, $n_{i}$ and $n_{e}$ are expected to be nearly equal in the bulk plasma for an argon discharge. However, the probe data here shows that $n_{i}$ is about $40-50 \%$ higher than $n_{e}$. An overestimate of $n_{i}$ may be due to additional ion-current induced by secondary electron emission from the tip surface as a result of impingement by ions, energetic neutrals and plasma radiation. The electron density may have been affected by the reflection and reemission of electrons on the tip surface. Also, in Langmuir probe measurements, the ion current is of the order few $\mathrm{mA}$ and far smaller than the electron current and hence, the ion density may have a higher error than electron density. The values of $n_{e}$ and $n_{i}$ should be respectively considered as the lower and upper limits of plasma density. A similar observation was previously made by Schwabedissan et $\mathrm{al}^{34}$. They measured $n_{e}$ by a plasma oscillation probe (POP) and found the values to be $40 \%$ higher than those using a 
Langmuir probe. POP is free of interefence from plasma potential oscillations, thin film deposition on probe tips in reactive mixtures, probe circuit resistance, and ionization and charge depletion near the probe.

\section{B. $\mathrm{CHF}_{3} / \mathrm{Ar}$ mixture}

Total ion flux, along with the most significant individual ion fluxes, as a function of gas pressure at $200 \mathrm{~W}$ for three gas mixtures of $\mathrm{CHF}_{3} / \mathrm{Ar}: 20 / 80,50 / 50$ and $80 / 20 \%$ are shown in Fig 5. The flux values are also listed in Table 2 where a comparison is made with the recent data of Wang et al.$^{18}$ for $50 \% \mathrm{CHF}_{3}: 50 \% \mathrm{Ar}$ at $10 \mathrm{mTorr}$. It is clear from the figure, as well as the table, that the total ion flux, except for the $20 \% \mathrm{CHF}_{3}$ case, decreases with increase in pressure. However, as will be seen later, the total ion density in the bulk increases with pressure only for $\mathrm{CHF}_{3}$-lean mixture and decreases otherwise. Two conclusions can then be drawn: (1) the observed behavior can be explained by that of the most dominant ions and (2) in mixtures, the ion flux (measured at the electrode) variation with pressure, etc. for a particular ion does not have to be similar to or necessarily follow the behavior of ion density in the bulk since there can be many ion loss channels (e.g. charge exchange collisions). From Table 2 and Fig. $5, \mathrm{Ar}^{+}$is the most dominant ion except in the $\mathrm{CHF}_{3}$-rich mixture. $\mathrm{Ar}^{+}$flux decreases with an increase in pressure for all three mixture ratios. This contrasts the behavior of $\mathrm{Ar}^{+}$flux in pure argon discharges where an increase with pressure is seen, (Fig. 3a) along with a similar dependence of the $\mathrm{Ar}^{+}$density in the bulk (Fig. $4 \mathrm{~b}$ ). The $\mathrm{Ar}^{+}$ion loss channel in a $\mathrm{CHF}_{3}$ mixture may be ${ }^{35}$

$$
\mathrm{Ar}^{+}+\mathrm{CHF}_{3} \rightarrow \text { Products, } \mathrm{k}=1.38 \times 10^{-9} \mathrm{~cm}^{3 / 5}
$$

The favorable products of this charge transfer reaction appear to be ${ }^{36} \mathrm{CF}_{3}{ }^{+}$and $\mathrm{CHF}_{2}{ }^{+}$.

$\mathrm{ArH}^{+}$also appears to be a significant component in $\mathrm{CHF}_{3} / \mathrm{Ar}$ mixtures except in $\mathrm{CHF}_{3}$-rich cases. Other possible $\mathrm{Ar}^{+}$ion loss channels may also be a source of $\mathrm{ArH}^{+}$production:

$$
\mathrm{Ar}^{+}+\mathrm{CHF}_{3} \rightarrow \mathrm{ArH}^{+}+\text {products }
$$




$$
\mathrm{Ar}^{+}+\mathrm{H}_{2} \rightarrow \mathrm{ArH}^{+}+\mathrm{H}
$$

In lean- $\mathrm{CHF}_{3}$ mixture, $\mathrm{ArH}^{+}$flux increases with pressure which may be due to reaction (5). $\mathrm{ArH}^{+}$ flux in rich- $\mathrm{CHF}_{3}$ is negligible since simultaneously the Ar content is low. Though an expected abundance of neutral $\mathrm{H}$ in these discharges would warrant consideration of

$$
\mathrm{Ar}^{+}+\mathrm{H} \rightarrow\left(\mathrm{ArH}^{+}\right)^{*}
$$

the cross section for this reaction is smaller than that of (6). In addition, a third body collision would be needed to release the excess energy and produce the ground state $\mathrm{ArH}^{+}$. It can happen at the surfaces of electrodes and chamber walls.

The most dominant $\mathrm{CH}_{\mathrm{x}} \mathrm{F}_{\mathrm{y}}$ ions, in order, are $\mathrm{CF}, \mathrm{CF}_{3}, \mathrm{CHF}_{2}$ and $\mathrm{CF}_{2}$. In $80 \% \mathrm{CHF}_{3}$ mixture, $\mathrm{CHF}_{2}$ is the second most dominant instead of $\mathrm{CF}_{3}$. The fluxes of all of the above ions increase with pressure in lean- $\mathrm{CHF}_{3}$ mixture $(20 \%)$ whereas they decrease (except $\mathrm{CF}$ ) in rich$\mathrm{CHF}_{3}$ mixture (80\%). While absolute values of these ion fluxes are of great interest, flux values normalized by the total flux are revealing since the total flux itself decreases with increase in $\mathrm{CHF}_{3}$ content and pressure (except for $20 \% \mathrm{CHF}_{3}$ ). Variation of the normalized values with pressure and $\mathrm{CHF}_{3}$ fraction in general is opposite to that of absolute fluxes.

Electron impact ionization of $\mathrm{CHF}_{3}$ produces, in order of decreasing abundance, $\mathrm{CHF}_{2}{ }^{+}$, $\mathrm{CF}_{3}{ }^{+}, \mathrm{CF}^{+}$and $\mathrm{CF}_{2}{ }^{+}$, according to Fourier transform mass spectrometry measurements ${ }^{36}$. However, a recent survey ${ }^{37}$ of $\mathrm{CHF}_{3}$ electron impact kinetics shows the order to be $\mathrm{CF}^{+}, \mathrm{CF}_{3}{ }^{+}$, $\mathrm{CHF}_{2}{ }^{+}$, and $\mathrm{CF}_{2}{ }^{+}$. For example, the respective partial ionization cross sections (in units of $10^{-20}$ $\mathrm{m}^{2}$ ) at $70 \mathrm{eV}$ are 2.35, 2.04, 0.41 and 0.17 . Electron impact on $\mathrm{CHF}_{3}$ also produces neutrals with $\mathrm{CF}_{3}$ and $\mathrm{CF}$ with larger cross sections than $\mathrm{CHF}_{2}, \mathrm{CF}_{2}$ and $\mathrm{CHF}^{37}$. The observed hierarchy of ion fluxes in the present work appears to be consistent with the electron impact kinetics in ref. 37 and charge exchange reactions (4). Other relevant reactions ${ }^{38}$ contributing to the observed fluxes include collision induced dissociation (CID) of $\mathrm{CF}_{3}{ }^{+}$: 


$$
\begin{aligned}
\mathrm{CF}_{3}^{+}+\mathrm{CHF}_{3} & \rightarrow \mathrm{CF}_{2}^{+}+\mathrm{F}+\mathrm{CHF}_{3} \\
& \rightarrow \mathrm{CF}^{+}+\mathrm{F}_{2}+\mathrm{CHF}_{3} \\
& \rightarrow \mathrm{C}^{+}+\mathrm{F}+\mathrm{F}_{2}+\mathrm{CHF}_{3}
\end{aligned}
$$

The cross sections for the above reactions are constant at about $5 \times 10^{-16} \mathrm{~cm}^{2}$ over $20-100 \mathrm{eV}$ of $\mathrm{CF}_{3}{ }^{+}$. The following dissociative charge transfer (DCT) reactions are also possible though the cross sections are smaller than for (8)-(10):

$$
\begin{aligned}
\mathrm{CF}_{3}^{+}+\mathrm{CHF}_{3} & \rightarrow \mathrm{CHF}_{2}^{+}+\mathrm{CF}_{4} \\
& \rightarrow \mathrm{CF}_{3}+\mathrm{CF}_{3}^{+}+\mathrm{H} \\
& \rightarrow \text { Products }\left(\mathrm{CF}_{2}^{+}, \mathrm{CF}^{+}, \mathrm{C}^{+} \ldots\right)
\end{aligned}
$$

As evident from Fig. 5 and Table 2, the minor ions $\mathrm{C}^{+}, \mathrm{F}^{+}, \mathrm{HF}^{+}, \mathrm{H}_{2} \mathrm{~F}^{+}, \mathrm{CO}^{+}$, and $\mathrm{O}_{2}^{+}$ contribute $2-5 \%$ to the total ion flux. The flux of $\mathrm{F}^{+}$is negligible over the entire range of conditions. The production of $\mathrm{HF}^{+}$, besides from e $+\mathrm{CHF}_{3} \rightarrow \mathrm{HF}^{+}+\mathrm{CF}_{2}$, may have also come from the electron-impact ionization of HF. The neutral $\mathrm{HF}$ production is from $\mathrm{e}+\mathrm{CHF}_{3} \rightarrow$ fluorocarbon ions $+\mathrm{HF}$, associative electron detachment reaction, $\mathrm{F}^{-}+\mathrm{H} \rightarrow \mathrm{HF}+\mathrm{e}$, and $\mathrm{CF}_{x}$ radicals reacting with atomic hydrogen by

$$
\begin{aligned}
& \mathrm{CF}_{3}+\mathrm{H} \rightarrow \mathrm{CF}_{2}+\mathrm{HF} \\
& \mathrm{CF}_{2}+\mathrm{H} \rightarrow \mathrm{CF}+\mathrm{HF} \\
& \mathrm{CF}+\mathrm{H} \rightarrow \mathrm{C}+\mathrm{HF}
\end{aligned}
$$

Since the reaction rates for these reactions are high $\left(\sim 10^{-11} \mathrm{~cm}^{3} /\right.$ molecule.sec $),{ }^{39}$ the presence of atomic hydrogen alters the fluorocarbon chemistry significantly. The phenomenon of "hydrogen scavenging" in fluorocarbon plasmas is a well-established mechanism for the reduction of fluorine due to the strong affinity of $\mathrm{H}$ for $\mathrm{F}^{40-42}$ However, this reaction requires a third body, so it takes place mostly at the electrode surfaces and reactor walls, and HF reenters the plasma. A large cross section for the reaction $\mathrm{e}+\mathrm{CHF}_{3} \rightarrow \mathrm{CF}_{3}{ }^{+}+\mathrm{H}$ (compared to $\mathrm{CF}_{3}+\mathrm{H}^{+}$production) 
can leave an abundance of $\mathrm{H}$ atoms in the plasma. The byproduct ion $\mathrm{H}_{2} \mathrm{~F}^{+}$might have come from reactions $\mathrm{HF}^{+}+\mathrm{H} \rightarrow \mathrm{H}_{2} \mathrm{~F}^{+}$and $\mathrm{HF}^{+}+\mathrm{CHF}_{3} \rightarrow \mathrm{H}_{2} \mathrm{~F}^{+}+\mathrm{CF}_{3}$. The contribution of $\mathrm{C}^{+}$ion remains in the $2-5 \%$ range. There is no sign of $\mathrm{SiF}_{\mathrm{x}}{ }^{+}$but a relatively small signal at 28 amu was observed. Though $\mathrm{Si}^{+}$and $\mathrm{CO}^{+}$have the same mass 28 and are indistinguishable by our QMF, this signal is assigned to $\mathrm{CO}^{+}$. The etching of the quartz window liberates oxygen atoms and may be the source of $\mathrm{CO}^{+}$as well as $\mathrm{O}_{2}^{+}$.

At least for one set of conditions $(10 \mathrm{mT})$, data is available from Wang et $\mathrm{al}^{18}$ for comparison as shown in Table 2. The order of relative intensities, but not the absolute values, of the major ions is nearly the same except for $\mathrm{Ar}^{+}, \mathrm{HF}^{+}$, and $\mathrm{C}^{+}$. Interestingly, the flux of $\mathrm{Si}^{+} / \mathrm{CO}^{+}$ seems to be the second most dominant in ref. 18 whereas the signal at $28 \mathrm{amu}$ in our work is weak. It is likely that the surface of the quartz window in ref. 18 must have been quite degraded to result in considerable amount of $\mathrm{Si}^{+} / \mathrm{CO}^{+}$when plasma comes in contact with it.

Figure 6 shows IEDs for two major ions $\mathrm{Ar}^{+}$and $\mathrm{CF}_{3}{ }^{+}$at $200 \mathrm{~W}$ and various pressures and gas mixtures. All the ions exhibit a single-peak energy distribution with a narrow energy spread $(\Delta E)$. The IEDs of heavy ions look nearly Gaussian, whereas the lighter ions, especially $\mathrm{C}^{+}$, (not shown here), exhibit a small high energy tail indicating higher initial kinetic energies in the bulk plasma. The FWHM of IEDs for all ions is in the range of 3-5 eV. It tends to broaden with increase in $\mathrm{CHF}_{3}$ concentration in the mixture, but is nearly invariant with pressure at a fixed $\mathrm{CHF}_{3} / \mathrm{Ar}$ ratio. $\Delta E$ increases inversely with ion mass $(M)$ as ${ }^{43} \Delta E \sim M^{-0.5}$. The mean ion energy $(\langle E\rangle)$ is computed directly from the numerical data of IED using

$$
<E_{i}>=\frac{\int E_{x} I_{x}}{\int I_{x}}
$$

Here, $I$ is the intensity. The $\left\langle E_{p}\right\rangle$ value is accurate to within $\pm 0.5 \mathrm{eV}$. Because a large number of ions is observed and all of them have almost the same $\left\langle E_{p}\right\rangle$ with a maximum variation of \pm 0.5 $\mathrm{eV}$, it is convenient to define an average $\left\langle E_{P}\right\rangle_{\text {ave }}$ which is plotted in Fig. 7. The average of mean 
energies decreases with an increase in pressure and increases with $\mathrm{CHF}_{3}$ concentration. Since the ion energy depends on $V_{p}$, the observed trend is consistent with Langmuir probe data discussed below.

Figure 8 shows Langmuir probe measurements of $V_{p}, T_{e}, n_{e}$, and $n_{i}{ }^{+}$at various pressures and gas composition. Probe measurements were repeated several times to estimate the standard deviation, and the $V_{p}$ measurements were found to be reproducible within $\pm 0.5 \mathrm{eV} . V_{p}$ tends to drop-off exponentially as the pressure is increased from 10 to $50 \mathrm{mTorr}$ in all three mixtures. Depending on operating conditions, $V_{p}$ is about $0.5-2.0 \mathrm{eV}$ higher than the $\left\langle E_{P}\right\rangle$ values measured by the EQPA, a trend which is similar to that in pure Ar plasmas discussed earlier. It is clear from Fig 8 that $V_{p}$ increases with the $\mathrm{CHF}_{3}$ content in the mixture. The behavior of $T_{e}$ is similar to that of $V_{p}$.

The $n_{e}$ and $n_{i}^{+}$exhibit a different pressure dependence compared to $V_{p}$ and $T_{e}$ and their behavior is also different for each mixture. Both $n_{e}$ and $n_{i}^{+}$drop off considerably with increase in $\mathrm{CHF}_{3}$ content. Since $\mathrm{CHF}_{3}$ is an electronegative gas, the increase in $\mathrm{CHF}_{3}$ content in the mixture is accompanied by an increase in attachment reactions, production of negative ions and a simultaneous drop in electron density. The $\mathrm{CHF}_{3}$-lean mixture is similar to an argon discharge and both electron and ion densities increase with pressure. When $\mathrm{CHF}_{3}$ content is $50 \%$ or above, the densities are nearly constant or decrease slightly in the 10-50 mTorr range. An increase in pressure results in an increase in gas density and can lead to increased attachment rates even if the cross sections are invariant with electron energy. In contrast, ionization rate may not increase despite an increase in gas density since the electron temperature and hence the ionization rate constant decrease with an increase in pressure. This is perhaps the reason why the electron density is invariant or exhibits a moderate decrease in the pressure range investigated.

\section{C. $\mathrm{CHF}_{3} / \mathrm{O}_{2} /$ Ar mixture}

Measurements were made at two RF powers (200 and $300 \mathrm{~W}$ ) and two gas pressures (30 and $50 \mathrm{~m}$ Torr) by adding $\mathrm{O}_{2}$ to $\mathrm{CHF}_{3} / \mathrm{Ar}$ with the $\mathrm{O}_{2}$ concentration fixed at $20 \%$ and varying the 
$\mathrm{CHF}_{3} / \mathrm{Ar}$ ratio for two conditions $\mathrm{CHF}_{3} / \mathrm{Ar} / \mathrm{O}_{2}: 40 / 40 / 20 \%$ and $60 / 20 / 20 \%$. Since admixing $\mathrm{O}_{2}$ with $\mathrm{CHF}_{3} / \mathrm{Ar}$ can significantly change the plasma chemistry, production of $\mathrm{CO}^{+}, \mathrm{CO}_{2}{ }^{+}, \mathrm{COF}^{+}$, $\mathrm{COF}_{2}{ }^{+}$, and $\mathrm{COF}_{3}{ }^{+}$ions and their neutrals is expected as a result of charge exchange reactions between oxygen products $\left(\mathrm{O}_{2}, \mathrm{O}, \mathrm{O}_{2}^{+}\right.$, and $\left.\mathrm{O}^{+}\right)$and $\mathrm{CHF}_{3}$ and its dissociation products $\left(\mathrm{CF}_{x}\right.$ neutrals and ions, and $\mathrm{C}^{+}$). Since there was no sign of $\mathrm{SiF}_{x}{ }^{+}$in $\mathrm{CHF}_{3} / \mathrm{Ar}$ mixtures in the previous section, and because of the presence of $\mathrm{O}_{2}$, the ion fluxes measured at masses 28,44 , 47, 66 and 85 amu should be largely of oxygen containing products $\mathrm{CO}^{+}$and $\mathrm{CO}_{2}{ }^{+}, \mathrm{COF}^{+}$, $\mathrm{COF}_{2}{ }^{+}$, and $\mathrm{COF}_{3}{ }^{+}$, respectively, with some amount of contribution at these masses from the corresponding silicon etch product ions $\left(\mathrm{Si}^{+}, \mathrm{SiO}^{+}, \mathrm{SiF}^{+}, \mathrm{SiF}_{2}{ }^{+}\right.$, and $\left.\mathrm{SiF}_{3}{ }^{+}\right)$from the quartz window. In the following, for simplicity, we assume the ions at these masses as oxygen containing ones. Ion fluxes measured by the EQPA for $\mathrm{Ar}^{+}$, significant fluorocarbon ions $\left(\mathrm{CF}_{3}{ }^{+}\right.$, $\mathrm{CF}_{2}{ }^{+}, \mathrm{CF}^{+}, \mathrm{CHF}_{2}{ }^{+}, \mathrm{COF}^{+}, \mathrm{COF}_{2}{ }^{+}$and $\mathrm{COF}_{3}{ }^{+}$), and $\mathrm{CO}^{+}, \mathrm{CO}_{2}{ }^{+}$and $\mathrm{O}_{2}{ }^{+}$are listed along with total flux in Table 3.

Examination of Table 3 reveals that the fluxes of all ions and the total show an increase when the power is increased from 200 to $300 \mathrm{~W}$. The ion flux at the electrode is the product $n_{i} v_{i}$ where $v_{i}$ is the ion directed velocity falling down the gradient due to the difference between $V_{p}$ and electrode potential, and $n_{i}$ is the ion density. In general, the ion densities everywhere in the plasma increase with power, which explains the observed effect on ion flux at the electrode. Further examination of Table 3 reveals that the two most dominant ions are $\mathrm{CF}_{3}{ }^{+}$and $\mathrm{Ar}^{+}$. The concentration of $\mathrm{Ar}^{+}$decreases when the $\mathrm{Ar}$ content in the feedgas is reduced. The next set of dominant ions includes $\mathrm{CO}^{+}, \mathrm{COF}^{+}, \mathrm{COF}_{2}^{+}$and $\mathrm{CO}_{2}^{+}$whose high concentration relative to $\mathrm{CHF}_{3}$. /Ar mixtures is due to the oxygen in the feedgas. The fluorocarbon ions $\mathrm{CHF}_{2}^{+}, \mathrm{CF}_{2}{ }^{+}$and $\mathrm{CF}^{+}$ complete the list of significant ions collected by the EQPA. The remaining ions $\left(\mathrm{ArH}^{+}, \mathrm{O}_{2}^{+}\right.$, $\mathrm{HF}^{+}, \mathrm{H}_{2} \mathrm{~F}^{+}, \mathrm{F}^{+}, \mathrm{O}^{+}$, and $\mathrm{C}^{+}$) together contribute about $5 \%$ of the total flux.

The effect of pressure on individual ion fluxes in general seems to be similar to the $\mathrm{CHF}_{3} / \mathrm{Ar}$ mixtures discussed earlier. Raising the concentration of $\mathrm{CHF}_{3}$ from 40 to $60 \%$ as expected results in higher fractions of $\mathrm{CF}_{3}, \mathrm{CHF}_{2}$, and $\mathrm{CF}_{2}$ in the mixture. For the same conditions of pressure and power, addition of $\mathrm{O}_{2}$ to $\mathrm{CHF}_{3} / \mathrm{Ar}$ appears to reduce the total positive ion flux as 
evident by a comparison of Tables 2 and 3. Oxygen, being an electronegative gas, would increase the negative ion population in the plasma. Correspondingly, a drop in electron density, electron temperature and $V_{p}$ is seen from the Langmuir probe data as will be discussed shortly. The IEDs of two major ions $\mathrm{Ar}^{+}$and $\mathrm{CF}_{3}{ }^{+}$in $\mathrm{CHF}_{3} / \mathrm{Ar} / \mathrm{O}_{2}$ mixtures are shown in Fig. 9. All the distributions in Fig. 9 exhibit a single peak and broadening of the IEDs occurs with an increase in pressure but not much with power or $\mathrm{CHF}_{3}$ content. The FWHM for all the ions is in the range of $2.5-6 \mathrm{eV}$ and the width is more for lighter ions such as $\mathrm{C}^{+}$. The average of the mean energies is between 14.5 and $16.5 \mathrm{eV}$ for the cases considered here which is about $5-8 \mathrm{eV}$ lower than for $\mathrm{C}_{\mathrm{HF}} / \mathrm{Ar}$ mixtures.

Figure 10 shows Langmuir probe data for $T_{e}$ and $V_{p}$ for $\mathrm{CHF}_{3} / \mathrm{Ar} / \mathrm{O}_{2}$ mixtures. As expected, power seems to have negligible effect on these quantities whereas an inverse relation with pressure is observed. Changing $\mathrm{CHF}_{3}$ content from 40 to $60 \%$ has negligible effect on $T_{e}$ and $V_{p}$ (not shown here); however, these values are about $0.6 \mathrm{eV}$ and $3.0 \mathrm{eV}$ smaller respectively at 10 mTorr compared to $\mathrm{CHF}_{3} / \mathrm{Ar}$ mixtures in Fig. 8. This may be attributed to the increased electronegativity due to the oxygen. As expected, both electron and ion densities in Fig. 11 increase with power. In the range of pressures investigated (10-50 mTorr), the effect of pressure in this weakly electronegative mixture is to reduce the electron and positive ion densities.

Finally, some representative electron energy distribution functions (EEDF) extracted from the Langmuir probe data are shown in Fig. 12. For pure argon, the slopes of the EEDF vary somewhat in the energy range studied here and hence, the EEDF is not truly Maxwellian. At low energies, a nearly Maxwellian distribution is seen; however, at higher energies $(>15 \mathrm{eV})$, a depletion is apparent due to inelastic collisions and loss of fast electrons to the wall. Changing the power from 100 to $200 \mathrm{~W}$ has only a modest effect on the EEDF. Higher pressure discharges exhibit higher densities at low energies and faster depletion at high energies. Addition of $\mathrm{CHF}_{3}$ appears to make the EEDF Maxwellian up to an energy range of $20 \mathrm{eV}$, beyond which the EEDF is slowly depleted. In a $\mathrm{CHF}_{3} / \mathrm{Ar} / \mathrm{O}_{2}(60: 20: 20)$ mixture, the EEDF appears nearly Maxwellian at $10 \mathrm{mTorr}$ again up to $20 \mathrm{eV}$ and the EEDF fall-off at higher energies is still not rapid. At 50 $\mathrm{mTorr}$, the onset of depletion occurs at lower energies. 


\section{Conclusions}

Total and individual fluxes and kinetic energy distributions of ions were measured in inductively coupled $\mathrm{RF}$ plasmas generated in a GEC cell in $\mathrm{Ar}, \mathrm{CHF}_{3} / \mathrm{Ar}$, and $\mathrm{CHF}_{3} / \mathrm{Ar} / \mathrm{O}_{2}$ mixtures. In pure Ar plasmas $\mathrm{Ar}^{+}$is the dominant ion at all pressures and powers and its flux was observed to increase with pressure and power. Our $\mathrm{Ar}$ results are in reasonable agreement with earlier data ${ }^{26,27}$ except in isolated cases. In the case of $\mathrm{CHF}_{3} / \mathrm{Ar}$ plasmas, the discharge is dominated by the ions $\mathrm{Ar}^{+}, \mathrm{ArH}^{+}, \mathrm{CF}_{3}^{+}, \mathrm{CHF}_{2}^{+}, \mathrm{CF}_{2}^{+}$, and $\mathrm{CF}^{+}$with a small contribution from $\mathrm{H}_{2} \mathrm{~F}^{+}, \mathrm{HF}^{+}, \mathrm{F}^{+}$and $\mathrm{C}^{+}$.

Charge exchange reactions appear to have significant impact on the ion kinetics and transport, and help to explain the observations. The IEDs of all ions exhibit a single narrow peak and broadening is observed with an increase in $\mathrm{CHF}_{3}$ content. The FWHM for all ions is in the range of 3-5 eV. Addition of $\mathrm{O}_{2}$ to $\mathrm{CHF}_{3} / \mathrm{Ar}$ considerably reduces the total ion flux and changes the relative population of $\mathrm{CF}_{x}^{+}$ions while promoting $\mathrm{COF}_{x}^{+}, \mathrm{CO}^{+}$and $\mathrm{CO}_{2}^{+}$production. Measurements of ion energies with EQPA and plasma potential with RF compensated Langmuir probe are consistent with each other. Langmuir probe data, particularly the effects of pressure and power on densities, electron temperature and plasma potential are in general agreement with simple global model predictions. ${ }^{33}$

\section{Acknowledgment}

The authors are grateful to Jeff Ifland for his technical support in setting up the GEC cell and Anthony Lambardi for his support in data collection and analysis. Work by Dr. Rao is supported by a NASA-ARC contract to ELORET. Work by JSK and MAC is supported by a grant from NASA-ARC to Stanford University. 


\section{References}

1. D.L. Flamm, V.M. Donnelly and D.E. Ibbotson, J. Vacuum Science Technology, B 1, 23 (1983).

2. K. Kirmse, A. Wendt, S. Disch, J. Wu, I. Abraham, J. Meyer, R. Breun, and R. C. Woods, J. Vac. Sci, Technol. B 14, 710 (1996).

3. D.L. Flamm and V.M. Donnelly: Plasma Chem. Plasma Proc. 1, 317 (1981).

4. J.W. Coburn, J. Appl. Phys. 50, 5210 (1979).

5. K. Maruyama, A. Sakai and T. Goto, J. Phys. D 26, 199 (1993).

6. T. Namura, H. Okada, Y. Naitoh, Y. Todokoro and M. Inoue, Jpn. J. Appl. Phys. 29, 2251 (1990).

7. D.M. Manos and D.L. Flamm, Plasma Etching: An Introduction, Academic, New York, 1989, Chapter 2

8. R. P. Jayaraman, R. T. McGrath, and G. A. Hebner, J. Vac. Sci. Technol. A 17, 1545 (1999).

9. X. Li, M. Schaepkens, G. S. Oehrlein, R. E. Ellefson, L. C. Frees, N. M. Mueller, and N. Korner, J. Vac. Sci. Technol. A 17, 2438 (1999).

10. T. Fukasawa, A. Kakamura, H. Shindo and Y. Horiike, Jpn. J. Appl. Phys. 33, 2139 (1994).

11. G.M.W. Kroesen, H.J. Lee, H. Moriguchi, H. Motomura, T. Shirafuji, K. Tachibana, J. Vac. Sci. Technol. A 16, 225, (1998).

12. N. R. Rueger, M. F. Doemling, M. Schaepkens, J.J. Beulens, T. E. F. M. Standaert, and G. S. Oehrlein, J. Vac. Sci. Technol. A 17, 2492 (1999)

13. M. Schaepkens, N. R. Rueger J. J. Beulens, X. Li, T. E. F. M. Standaert, P. J. Matsuo, and G. S. Oehrlein, J. Vac. Sci. Technol. A 17, 3272 (1999).

14. S. Samukawa, Jpn. J. Appl. Phys. 33, 2133 (1994)

15. K. Takahashi, M. Hori, and T. Goto, J. Vac. Sci. Technol. A 14, 2011 (1996).

16. K. H. R. Kirmse, A. E. Wendt, S. B. Disch, J. Z. Wu, I. C. Abraham, J. A. Meyer, R. A. Breun, and R. C. Woods, J. Vac. Sci. Technol. B14, 710 (1996).

17. T. Akimoto, S. Furuoya, K. Harasima, and E. Ikawa, Jpn. J. Appl. Phys. 33, 2151 
(1994).

18. Y. Wang, M. Misakian, A. N. Goyette, and J. K. Olthoff, private communcation.

19. D. Bose, T. R. Govindan, and M. Meyyappan, J. Electrochem. Soc., 146, 2705 (1999).

20. D. Zhang and M. Kushner, J. Appl. Phys., 87, 1060 (2000).

21. I. G. Kouznetsov, A. J. Lichtenberg, and M. A. Lieberman, Plasma. Sources Sci. Technol. 5, 662 (1996).

22. J. T. Gudmundson and M. A. Lieberman, Plasma Sources Sci. Technol. 7, 1 (1998).

23. J. K. Olthoff and K. E. Greenberg, J. Res. Natl. Inst. Stand. Technol., 100, 401 (1995).

24. P. A. Miller, G. A. Hebner, K. E. Greenberg, P. D. Pochan, and B. A. Aragon, J. Res. Natl. Inst. Stand. Technol., 100, 427 (1995).

25. M. Schaepkens, R. C. M. Bosch, T. E. F. M. Standaert, and G. S. Oehrlein, J. Vac. Sci. Technol. A 16, 2099 (1998).

26. J. R. Woodworth, M. E. Riley, D. C. Meister, and B. P. Aragon, J. Appl. Phys. 80, 1304 (1996).

27. Y. Wang and J. K. Olthoff, J. Appl. Phys. 85, 6360 (1999).

28. SmartProbe: Installation and Software manual, WI-223.129.084.Rev 0, Scientific Systems, Ltd. (1997).

29. J. V. Scanlan and M. B. Hopkins, J. Vac. Sci. Technol. A 10, 1207 (1992).

30. J. G. Laframboise, Rarified Gas Dynamics, ed. J. H. de Leeuw (New York: Academic), 22 (1965).

31. U. Kortsagen and M. Zethoff, Plasma Sci. Technol., 4, 541 (1995).

32. J. Mahoney, A. E. Wendt, E. Barrios, C. J. Richards, and J. L. Shohet, J. Appl. Phys. 76, 2041 (1994).

33. M. A. Lieberman and A. J. Lichtenberg, Principles of Plasma Discharges and Materials Processing (Wiley, New York, 1994).

34. A. Schwabedissen, E. C. Benck, and J. R. Roberts, Plasma. Sci. Technol. 7, 119 (1998).

35. M. Chau and M.T. Bowers, Int. J. Mass Spectrom. Ion Phys. 23, 191 (1977).

36. C.Q. Jiao, R. Nagpal and P.D. Haaland, Chem. Phys. Lett. 269, 117 (1997).

37. L.G. Christophorou, J.K. Olthoff, and M.V.V.S. Rao, J. Phy. Chem. Ref. Data, 26, 1 (1997). 
38. B. L. Peko and R. L. Champion, private communication.

39. C. Tsai and D. L. McFaden, J. Phys. Chem. 93, 2471 (1989)

40. G.S. Oehrlein and H.L. Williams, J. Appl. Phys. 62, 662 (1987).

41. J. P. Simko and G.S. Oehrlein, J. Electrochem. Soc. 138, 2748 (1991).

42. W. H. Chang, I. Bello, and W. M. Lau, J. Vac. Sci. Technol. A 11, 1221 (1993).

43. J.W. Coburn and E. Kay, J. Appl. Phys. 43, 4965 (1972). 


\section{Figure Captions}

1. Schematic of the experiment

2. Power coupling efficiency

3. Data on $\mathrm{Ar}^{+}$(a) ion flux, (b) IED and (c) mean energy. Published data from ref. 26 and 27 are also shown.

4. Langmuir probe data for pure argon. (a) $V_{p}$ and $T_{e}$ (b) $n_{e}$ and $n_{i}$

5. Total and individual ion fluxes at $200 \mathrm{~W}$ for three $\mathrm{CHF}_{3} / \mathrm{Ar}$ mixtures

6. IEDs of (a) $\mathrm{Ar}^{+}$and (b) $\mathrm{CF}_{3}{ }^{+}$at $200 \mathrm{~W}$, various pressures and $\mathrm{CHF}_{3} / \mathrm{Ar}$ ratios.

7. Mean ion energy in CHF3:Ar mixtures as a function of pressure at $200 \mathrm{~W}$.

8. Langmuir probe data at $200 \mathrm{~W}$ for $\mathrm{CHF}_{3} / \mathrm{Ar}$ (a) $\mathrm{V}_{\mathrm{p}}$ and $\mathrm{T}_{e}$ (b) $\mathrm{n}_{\mathrm{e}}$ and $\mathrm{n}_{\mathrm{i}}$

9. IEDS of $\mathrm{Ar}^{+}$and $\mathrm{CF}_{3}{ }^{+}$in $\mathrm{CHF}_{3} / \mathrm{Ar} / \mathrm{O}_{2}$ mixtures.

10. Langmuir probe data for electron temperature $\left(\mathrm{T}_{e}\right)$ and plasma potential $\mathrm{V}_{\mathrm{p}}$ in $\mathrm{CHF} / \mathrm{Ar} / \mathrm{O}_{2}$ mixtures.

11. Measured electron and ion densities in $\mathrm{CHF}_{3} / \mathrm{Ar} / \mathrm{O}_{2}$ (a) 40:40:20 and (b) 60: 20:20 mixtures

\section{Table Captions}

1. Total and transmitted ion flux $\left(\mathrm{mA} / \mathrm{cm}^{2}\right)$ at various conditions.

2. Individual ion fluxes $\left(\mathrm{mA} / \mathrm{cm}^{2}\right)$ in $\mathrm{CHF}_{3} / \mathrm{Ar}$ mixtures at $200 \mathrm{~W}$. Data from ref. $18 \mathrm{in}$ parenthesis.

3. Individual ion fluxes $\left(\mathrm{mA} / \mathrm{cm}^{2}\right)$ in $\mathrm{CHF}_{3} / \mathrm{A}_{\mathrm{r}} / \mathrm{O}_{2}$ mixtures. 


\begin{tabular}{|c|c|c|c|c|c|c|c|c|c|c|}
\hline \multicolumn{2}{|c|}{ Gas Mixture } & \multirow[t]{2}{*}{ Power, Watts } & \multicolumn{2}{|c|}{10 mTorr } & \multicolumn{2}{|c|}{20 mTorr } & \multicolumn{2}{|c|}{30 mTorr } & \multicolumn{2}{|c|}{50 mTorr } \\
\hline & & & Total & Trans & Total & Trans & Total & Trans & Total & Trans \\
\hline \multirow[t]{3}{*}{$\mathrm{Ar}$} & \multirow[t]{3}{*}{ Pure } & 100 & 10.19 & 6.84 & 12.24 & 6.54 & 14.71 & 6.15 & 16.77 & 5.56 \\
\hline & & 200 & 19.76 & 9.37 & 21.39 & 7.95 & 24.24 & 7.33 & 26.69 & 6.11 \\
\hline & & 300 & 24.45 & 9.68 & 27.50 & 8.35 & 31.07 & 7.54 & 33.27 & 6.52 \\
\hline \multirow[t]{3}{*}{$\mathrm{CHF}_{3}: \mathrm{Ar}$} & $20: 80$ & 200 & 15.00 & 7.21 & 14.22 & 6.21 & 14.18 & 5.61 & 15.42 & 5.42 \\
\hline & $50: 50$ & 200 & 9.54 & 4.93 & 7.70 & 4.32 & 6.58 & 3.77 & 5.20 & 3.30 \\
\hline & $80: 20$ & 200 & 5.55 & 3.41 & 4.33 & 2.65 & 4.01 & 2.28 & 3.60 & 1.83 \\
\hline \multirow[t]{4}{*}{$\mathrm{CHF}_{3}: \mathrm{Ar}: \mathrm{O}_{2}$} & \multirow[t]{2}{*}{$40: 20: 40$} & 200 & 6.87 & 4.52 & 5.22 & 3.41 & 4.34 & 2.77 & 2.85 & 1.93 \\
\hline & & 300 & 10.88 & 5.95 & 8.99 & 4.91 & 7.63 & 4.21 & 5.97 & 3.44 \\
\hline & \multirow[t]{2}{*}{$60: 20: 20$} & 200 & 5.97 & 4.09 & 4.42 & 3.05 & 3.16 & 2.27 & 1.91 & 1.44 \\
\hline & & 300 & 9.54 & 5.79 & 7.33 & 4.68 & 6.11 & 3.87 & 4.01 & 2.75 \\
\hline
\end{tabular}




\begin{tabular}{|c|c|c|c|c|c|c|c|c|c|c|}
\hline \multicolumn{4}{|c|}{$\mathrm{CHF}_{3}: \mathrm{Ar}, 20: 80$} & \multicolumn{3}{c|}{$\mathrm{CHF}_{3}: \mathrm{Ar}, 50: 50$} & \multicolumn{3}{c|}{$\mathrm{CHF}_{3}: \mathrm{Ar}, 80: 20$} \\
\hline Ion & $10 \mathrm{mT}$ & $30 \mathrm{mT}$ & $50 \mathrm{mT}$ & $10 \mathrm{mT}$ & $10 \mathrm{mT}$ & $30 \mathrm{mT}$ & $50 \mathrm{mT}$ & $10 \mathrm{mT}$ & $30 \mathrm{mT}$ & $50 \mathrm{mT}$ \\
\hline $\mathrm{CF}_{3}{ }^{+}$ & 0.34 & 0.45 & 1.06 & 0.67 & $(0.31)^{*}$ & 1.02 & 0.89 & 0.81 & 0.54 & 0.61 \\
$\mathrm{CHF}_{2}^{+}$ & 0.31 & 0.31 & 0.78 & 0.71 & $(0.31)^{*}$ & 0.78 & 0.69 & 1.13 & 0.99 & 1.15 \\
$\mathrm{CF}_{2}{ }^{+}$ & 0.21 & 0.26 & 0.51 & 0.61 & $(0.15)^{*}$ & 0.51 & 0.42 & 0.71 & $0.5 \mathrm{I}$ & 0.40 \\
$\mathrm{ArH}^{+}$ & 0.27 & 0.77 & 1.44 & 0.30 & $(0.06)^{*}$ & 0.24 & 0.19 & 0.06 & 0.04 & 0.02 \\
$\mathrm{Ar}^{+}$ & 13.24 & 11.38 & 9.09 & 5.80 & $(1.25)^{*}$ & 2.42 & 1.27 & 0.96 & 0.31 & 0.20 \\
$\mathrm{O}_{2}^{+}$ & 0.02 & 0.02 & 0.04 & 0.01 & $(0.02)^{*}$ & 0.04 & 0.05 & 0.04 & 0.05 & 0.04 \\
$\mathrm{CF}^{+}$ & 0.32 & 0.50 & 1.20 & 1.00 & $(0.38)^{*}$ & 1.11 & 1.30 & 1.19 & 1.28 & 1.03 \\
$\mathrm{CO}^{+}$ & 0.02 & 0.01 & 0.26 & 0.01 & $(0.40)^{*}$ & 0.05 & 0.03 & 0.01 & 0.01 & 0.00 \\
$\mathrm{H}_{2} \mathrm{~F}^{+}$ & 0.02 & 0.08 & 0.34 & 0.03 & $(0.10)^{*}$ & 0.14 & 0.17 & 0.06 & 0.06 & 0.04 \\
$\mathrm{HF}^{+}$ & 0.14 & 0.18 & 0.25 & 0.21 & $(0.20)^{*}$ & 0.12 & 0.08 & 0.23 & 0.09 & 0.04 \\
$\mathrm{~F}^{+}$ & 0.03 & 0.02 & 0.03 & 0.02 & $(0.03)^{*}$ & 0.02 & 0.01 & 0.08 & 0.03 & 0.01 \\
$\mathrm{C}^{+}$ & 0.08 & 0.20 & 0.43 & 0.18 & $(0.16)^{*}$ & 0.12 & 0.11 & 0.26 & 0.09 & 0.05 \\
& & & & & & & & & & \\
\hline $\mathrm{Total}^{+}$ & 15.00 & 14.18 & 15.42 & 9.54 & $(3.37)^{*}$ & 6.58 & 5.20 & 5.55 & 4.01 & 3.60 \\
\hline
\end{tabular}

*Wang et al. 


\begin{tabular}{|c|c|c|c|c|c|c|c|c|}
\hline \multicolumn{5}{|c|}{$\mathrm{CHF}_{3}:$ Ar: $\mathrm{O}_{2}, 40: 40: 20$} & \multicolumn{4}{|c|}{$\mathrm{CHF}_{3}: \mathrm{Ar}: \mathrm{O}_{2}, 60: 20: 20$} \\
\hline \multicolumn{3}{|c|}{$200 \mathrm{~W}$} & \multicolumn{2}{|c|}{$300 \mathrm{~W}$} & \multicolumn{2}{|c|}{$200 \mathrm{~W}$} & \multicolumn{2}{|c|}{$300 \mathrm{~W}$} \\
\hline Ion & $30 \mathrm{mTorr}$ & $50 \mathrm{mT}$ Trr & 30 mTorr & $50 \mathrm{mT}$ Trt & $30 \mathrm{mT}$ Trr & $50 \mathrm{mTorr}$ & $30 \mathrm{mTorr}$ & $50 \mathrm{~m}$ Torr \\
\hline $\mathrm{COF}_{3}^{+}$ & 0.33 & 0.08 & 0.65 & 0.28 & 0.10 & 0.03 & 0.36 & 0.14 \\
\hline $\mathrm{CF}_{3}^{+}$ & 0.95 & 1.41 & 1.10 & 2.17 & $1.31^{\circ}$ & 0.77 & 2.29 & 1.69 \\
\hline $\mathrm{COF}_{2}^{+}$ & 0.37 & 0.16 & 0.37 & 0.28 & 0.17 & 0.09 & 0.31 & 0.16 \\
\hline $\mathrm{CHF}_{2}^{+}$ & 0.19 & 0.12 & 0.11 & 0.13 & 0.69 & 0.59 & 0.63 & 0.67 \\
\hline $\mathrm{CF}_{2}^{+}$ & 0.15 & 0.13 & 0.27 & 0.37 & 0.18 & 0.09 & 0.46 & 0.30 \\
\hline $\mathrm{COF}^{+}$ & 0.42 & 0.28 & 0.85 & 0.60 & 0.19 & 0.09 & 0.54 & 0.28 \\
\hline $\mathrm{CO}_{2}^{+}$ & 0.19 & 0.10 & 0.41 & 0.20 & 0.10 & 0.04 & 0.19 & 0.08 \\
\hline $\mathrm{ArH}^{+}$ & 0.04 & 0.02 & 0.11 & 0.07 & 0.01 & 0.00 & 0.02 & 0.01 \\
\hline $\mathrm{Ar}^{+}$ & 0.80 & 0.25 & 1.69 & 0.81 & 0.08 & 0.05 & 0.20 & 0.11 \\
\hline $\mathrm{O}_{2}^{+}$ & 0.13 & 0.05 & 0.25 & 0.09 & 0.03 & 0.02 & 0.08 & 0.04 \\
\hline $\mathrm{CF}^{+}$ & 0.13 & 0.10 & 0.37 & 0.39 & 0.13 & 0.06 & 0.41 & 0.27 \\
\hline $\mathrm{CO}^{+}$ & 0.49 & 0.10 & 0.95 & 0.41 & 0.12 & 0.06 & 0.40 & 0.17 \\
\hline $\mathrm{H}_{2} \mathrm{~F}^{+}$ & 0.04 & 0.02 & 0.09 & 0.05 & 0.02 & 0.01 & 0.05 & 0.03 \\
\hline $\mathrm{HF}^{+}$ & 0.02 & 0.01 & 0.07 & 0.03 & 0.01 & 0.01 & 0.04 & 0.02 \\
\hline $\mathbf{F}^{+}$ & 0.01 & 0.01 & 0.02 & 0.01 & 0.00 & 0.00 & 0.01 & 0.00 \\
\hline $\mathrm{O}^{+}$ & 0.05 & 0.01 & 0.20 & 0.05 & 0.01 & 0.00 & 0.05 & 0.01 \\
\hline $\mathrm{C}^{+}$ & 0.02 & 0.01 & 0.11 & 0.04 & 0.01 & 0.00 & 0.06 & 0.02 \\
\hline Total & 4.34 & 2.85 & 7.63 & 5.97 & 3.16 & 1.91 & 6.11 & 4.01 \\
\hline
\end{tabular}

